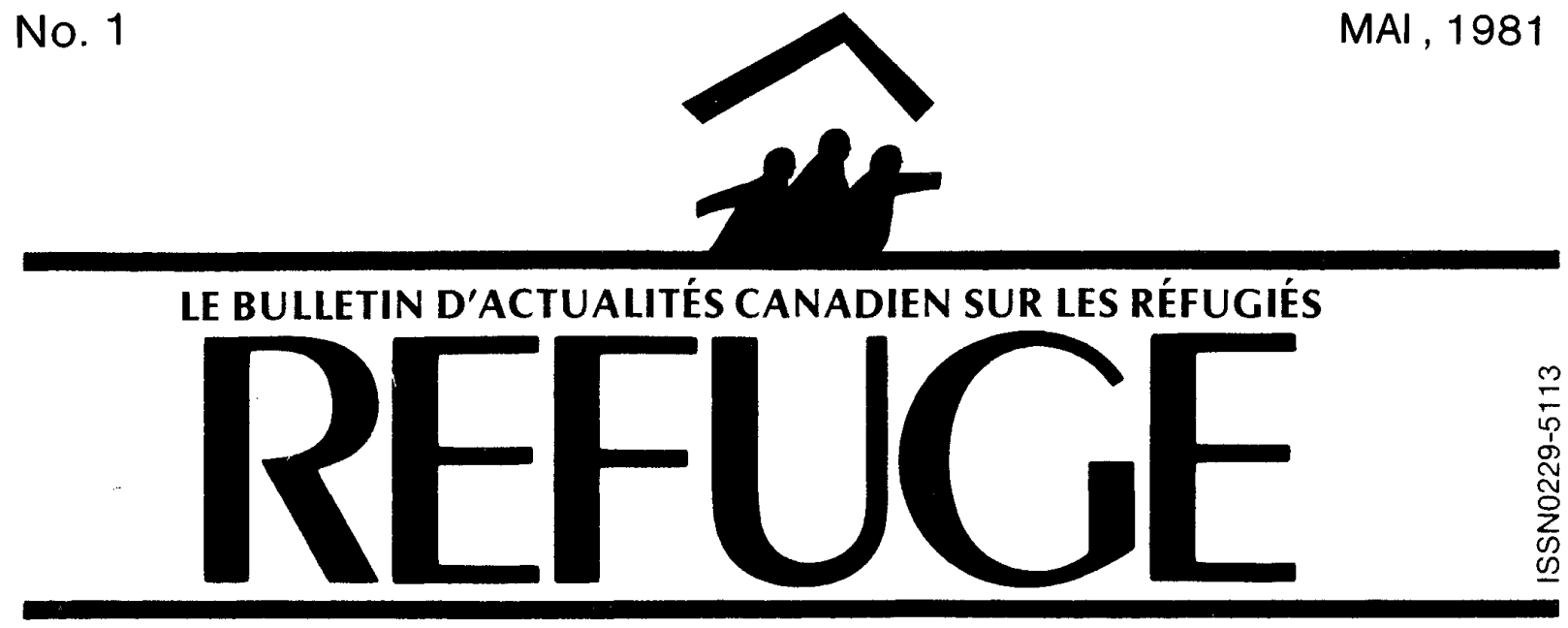

\title{
MOT DU RÉDACTEUR EN CHEF
}

Le terme "refuge" désigne un lieu où l'on se retire pour échapper à un danger ou pour se mettre en sûreté. Les Israélites avaient édifié des cités de refuge. Au cours des siècles, les marins ont cherché des ports pour mettre leurs navires à l'abri des tempêtes. II n'est donc pas surprenant que le Petit Robert définisse le terme "réfugié" comme étant "une personne qui a dû fuir le lieu qu'elle habitait pour échapper à un danger". On appelait "réfugiés" les protestants de France qui s'expatrièrent après la révocation de l'édit de Nantes au 17 e siècle pour aller s'établir dans les Flandres et en Amérique, parce que, victimes de persécution politique et religieuse, ils ont trouvé refuge dans un pays étranger.

L'acception contemporaine du terme est cependant différente. Aujourd'hui, un réfugié est un individu poussé par la crainte à fuir son pays d'origine et qui n'a plus de patrie. Que ce soit une guerre, un cataclysme ou la persécution qui motive la fuite du "réfugié", l'usage contemporain de ce mot désigne une personne sans refuge, sans abri, sans foyer.

L'évolution de la signification du terme "réfugié" traduit l'efrayante réalité et l'ampleur du problème actuel des réfufiés dans le monde. Donner refuge à plus de 13 millions d'êtres humains de diverses origines dans notre monde troublé, n'est pas tâche facile.

Le Canada cependant est une terre de refuge. Au cours des cinq dernières années, il s'est maintenu en tête des pays qui accueillent le plus grand nombre de réfugiés en rapport avec leur population. Une telle participation nous aura sensibilisés intensément à l'infortune des réfugiés et aura confirmé notre engagement à leur prêter secours.

Mais étant donné que le réétablissement au Canada ne constitue une solution appropriée que pour un nom- bre restreint de réfugiés, nos efforts doivent porter sur une gamme plus étendue d'activités: nous pourrions par exemple fournir de la nourriture, de l'eau et des médicaments aux réfugiés à l'étranger ou encore rendre l'asile temporaire au Canada plus facile d'accès.

En outre, nous faisons face à des problèmes aigus en voulant fournir aux réfugiés non seulement un lieu sûr, mais aussi une nouvelle patrie où ils pourront s'exprimer dans leur langue, occuper un emploi adapté à leurs talents et à leur formation et envisager l'avenir avec espoir.

Le Canada a démontré qu'il voulait et qu'il pouvait s'attaquer à ces problèmes. REFUGE vise précisément à faciliter ce processus en se faisant le porte parole des divers organismes de parrainage à travers le monde, en faisant connaître la politique canadienne et, ce qui est le plus important, en citant, certaines initiatives locales a titre d'exemples qui pourraient s'avérer utiles dans notre travail. Cet échange de renseignements ne sera possible que si vous qui oeuvrez auprès des réfugiés nous faites part de vos propres expériences, de vos connaissances, de vos opinions et de vos trouvailles en nous envoyant des lettres, des articles, des annonces et des suggestions.

REFUGE pour sa part s'efforcera d'éviter le piège de la partisanerie, ce qui est essentiel pour encourager la collaboration de tous. Divers points de vue y seront exprimés, ses sources de financement (y compris l'appui financier de ses lecteurs) seront variées et, ce qui est plus important encore, son conseil de rédaction sera composé de personnes déjà impliquées dans des mouvements d'aide aux réfugiés.

J'espère vivement que REFUGE se révélera une publication stimulante et utile. J'ai la certitude que son succès sera tributaire de la participation active de tous les Canadiens intéressés.

REFUGE se veut un forum qui, à travers ses échanges d'idées et d'opinions suscitera l'intérêt et la participation des Canadiens aux programmes d'aide aux réfugiés, tant à l'échelle locale qu'internationale. 